\title{
Role of Inflammation in Oral Squamous Cell Carcinoma
}

\author{
Kıvanç Bektaş-Kayhan \\ Istanbul University, Faculty of Dentistry, \\ Department of Oral Surgery and Medicine \\ Turkey
}

\section{Introduction}

The most common malignant oral disease is oral squamous cell carcinoma (OSCC), and most of the time this term is used synonymously with oral cancer (1). Oral cancer is a serious and growing problem in many parts of the world. When grouped together with pharyngeal cancers, it is the sixth most common cancer globally (2). There is a wide geographic variation in the incidence of this cancer. This usually depends on the culture, life style factors and level of country development (1). In the South and Southeast Asia, parts of Western (e.g. France) and Eastern Europe, parts of Latin America and the Caribbean and in the Pacific regions, oral cancer rates are higher than the other parts of the world (3). The major risk factors of the disease are cigarette smoking (4), alcohol abuse (5), and viral infections such as HPV (6). These risk factors are primarily based on life style but do not adequately explain the increasing incidence of this cancer among the young population (7) and non- smoking females (8). In addition, genetic susceptibility may play an important role $(9,10$, 11). Epidemiological studies have shown that chronic inflammation is associated with various types of cancer (12). It is estimated that $15-20 \%$ of all deaths from cancer worldwide are linked to infections and inflammatory responses (13). In the last two decades most chronic diseases, including cancer, have been associated with dysregulated inflammatory response. The identification of transcript factors such as NF-KB, AP-1 and STAT3 and their gene products such as tumor necrosis factor (TNF), interleukin-1 (IL-1), interleukin-6 (IL-6), chemokines, cyclooxygenase-2 (COX-2), 5 lipooxygenase, matrix metalloproteases (MMP) and vascular endothelial growth factor (VEGF), adhesion molecules and others has provided the molecular basis for the role of inflammation in cancer. These inflammatory pathways are activated by tobacco, stress, dietary agents, obesity, alcohol, infectious agents, irradiation, and environmental stimuli, which, combined, account for as much as 95\% of all cancers (14).

\section{Inflammation and cancer}

\subsection{A short overview of inflammation}

Inflammation is a crucial, complex host defense against biologic, chemical, physical, and endogenous irritants. The contribution of inflammation to physiological and pathological processes such as wound healing and infection needs to be understood for a better understanding of the role of inflammation in cancer formation. When tissues are injured, a 
multifactorial network of chemical signals initiates and maintains a host response designed to heal the afflicted tissue. The response includes activation and directed migration of leukocytes (neutrophils, monocytes and eosinophils) from the venous system to sites of damage. Neutrophils are thought to coordinate recruitment of these inflammatory cells to sites of tissue injury and to the provisional extracellular matrix (ECM). This is a four-step mechanism: first come selectins that include adhesion molecules (L- P-, and E-selectin) that facilitate rolling along the vascular endothelium; signals are then generated that activate and upregulate leukocyte integrins mediated by cytokines and leukocyte-activating molecules; neutrophils on the surface of the vascular endothelium are immobilized by means of tight adhesion through a $4 \beta 1$ and a $4 \beta 7$ integrins binding to endothelial vascular cell-adhesion molecule-1 (VCAM-1) and MadCAM-1, respectively; this brings about transmigration through the endothelium to sites of injury and is presumably facilitated by extracellular proteases, such as matrix metalloproteinases (MMPs) (15).

\section{Cellular components}

Platelet activation and aggregation, in addition to accelerating coagulation, provide a bolus of secreted proteins and a-granule contents to the immediate area, all of which help initiate and accelerate the inflammatory response by the host. Examples of such secreted proteins include arachidonic acid metabolites, heparin, serotonin, thrombin, coagulation factors (factor V), adhesive proteins (fibrinogen and von Willebrand factor), plasma proteins (immunoglobulin- $\gamma$ and albumin), cell growth factors (platelet-derived growth factor (PDGF), platelet-derived angiogenesis factor, transforming growth factor- $\alpha$ (TGF- $\alpha$ ), TGF- $\beta$ and basic fibroblast growth factor (bFGF)), enzymes (heparinase and factor XIII) and protease inhibitors (plasminogen activator inhibitor-1, a2-macroglobulin and a2-antiplasmin). Following platelet-induced hemostasis and release of TGF- $\beta 1$ and PDGF, formation of granulation tissue is facilitated by chemotaxis of neutrophils, monocytes, fibroblasts and myofibroblasts, as well as synthesis of new extracellular matrix (ECM) and neoangiogenesis.

Neutrophils produce cytokines/chemokines required for effector cell recruitment, activation and response (16). These phagocytic cells initiate wound healing by serving as a source of early-response pro-inflammatory cytokines such as tumor necrosis factor- $\alpha$ (TNF- $\alpha)$ (17), and interleukin (IL)-1 $\alpha$ and IL-1 $\beta$ (18). These cytokines mediate leukocyte adherence to the vascular endothelium, restricting leukocytes to areas of repair, and initiate repair by inducing expression of matrix metalloproteinases (MMPs) and keratinocyte growth factor (KGF/FGF-7) by fibroblasts (19).

Mononuclear phagocytes migrate from the venous system to the site of tissue injury, in response to tissue injury. Chemotactic factors, including PF-4, TGF- $\beta$, PDGF, chemokines (monocyte chemoattractant protein-1, -2 and -3 (MCP-1/CCL2, MCP-2/CCL8 and MCP3/CCL7), macrophage inflammatory protein-1 $\alpha$ and $-1 \beta$ (MIP-1 $\alpha / C C L 3$ and MIP$1 \beta /$ CCL4), and the cytokines IL-1 $\beta$ and TNF- $\alpha$, guide them to the site. Deployment of monocytes/macrophages to the site of injury causes the number of neutrophils to decline as they are phagocyted by macrophages. Once present, however, they differentiate into mature macrophages or immature dendritic cells. After activation, macrophages are the main source of growth factors and cytokines (TGF- $\beta 1$, PDGF, bFGF, TGF- $\alpha$, insulin-like growth factor (IGF)-I and -II, TNF-a and IL-1) that modulate tissue repair. Cells in their local microenvironment (e.g., endothelial, epithelial, mesenchymal or neuroendocrine cells) are 
profoundly affected by macrophage products $(20,21)$. Following their activation, mast cells are full of stored and newly synthesized inflammatory mediators. This cell type synthesizes and stores histamine, cytokines and proteases complexed to highly sulphated proteoglycans within granules, as well as producing, lipid mediators and cytokines upon stimulation. Once activated by complement or by the binding of antigens to immunoglobulin E (IgE) bound to high-affinity IgE receptors (FcERI), mast cells degranulate, releasing mediators including heparin, heparinase, histamine, MMPs and serine proteases, and various polypeptide growth factors, including bFGF and vascular endothelial growth factor. These function both in the early initiation phase of inflammation (e.g. vascular reaction and exudation), and in the late phase where leukocyte accumulation and wound healing takes place (15).

\section{Chemotactic cytokines}

Chemokines represent the largest family of cytokines ( $\sim 41$ human members), forming a complex network for the chemotactic activation of all leukocytes. Chemokine receptors, members of the seven-transmembrane-spanning G-protein-coupled receptors, vary by cell type and degree of cell activation (22). There is considerable redundancy in chemokinereceptor interaction, as many ligands bind to different receptors.

The composition of chemokines produced at sites of tissue wounding not only recruits downstream effector cells, but also dictates the natural evolution of immune reactivity. For example, MCP-1/CCL2, a potent chemotactic protein for monocytes and lymphocytes, simultaneously induces expression of lymphocyte-derived IL-4 in response to antigen challenge while decreasing expression of IL-12 (23). The net effect of this alteration facilitates a switch from a TH1-type to a TH2-type inflammatory response (15).

\section{Tissue repair}

In response to wounding, fibroblasts migrate into the wound bed and initially secrete collagen type III, which is later replaced by collagen type I. Synthesis and deposition of these collagens by fibroblasts is stimulated by factors including TGF- $\beta 1,-\beta 2$ and $-\beta 3$, PDGF, IL-1 $\alpha,-1 \beta$ and -4 , and mast cell tryptase. Once sufficient collagen has been generated, its synthesis stops; thus, during wound repair, production as well as degradation of collagens is under precise spatial and temporal control.

The final phase of the healing process is re-epithelialization and migration of epithelial cells across this amalgam. This is a process that requires both dissolution of the fibrin clot and degradation of the underlying dermal collagen. Epithelial cells at the leading edge of the wound express the uPA receptor, which is important for focal activation of uPA and the collagenolytic enzymes of the MMP family. In the absence of the fibrinolytic enzyme plasmin, derived from plasminogen after activation by uPA and tissue-PA, reepithelialization is dramatically delayed (24).

The profile of cytokine/chemokines persisting at an inflammatory site is important in the development of chronic disease. The pro-inflammatory cytokine TNF-a (tumor necrosis factor- $\alpha$ ) controls inflammatory cell populations and also mediates many of the other aspects of the inflammatory process. In addition, TGF- $\beta 1$ is important, because it influences the processes of inflammation and repair in both a positive and negative manner. The key 
idea is that normal inflammation - i.e., inflammation associated with wound healing - is usually self-limiting; however, dysregulation of any of the converging factors can lead to abnormalities and ultimately, pathogenesis. This seems to be the case during neoplastic progression (15).

\section{OSCC and inflammation}

Pathologists have known for more than 100 years that almost all tumors are accompanied by inflammatory cells. At present, there is almost unanimous agreement about the causes. The functional association dates back to Virchow, who in 1863 hypothesized that cancer arises in sites of inflammation (12). Today it is accepted that chronic inflammation resulting from low grade, persistent chemical, bacterial, viral agents predisposes the formation of the preneoplastic foci and promotes tumor development (25).

Infectious agents such as Helicobacter pylori, with its strong association to gastric cancer, or the relationship of non-infectious chronic inflammation like chronic pancreatitis to pancreatic cancer $(12,15)$ are examples of infection and inflammation leading to tumor growth. Chronic inflammation caused by infections and chronic irritations are being deeply researched in order to locate the exact mechanism that triggers the cancer.

\subsection{Infections of oral cavity and OSCC}

OSCC is a multifactorial disease where no single clearly recognizable causative factor has been identified. Inflammation or infection-related carcinogenesis of the oral cavity is currently under investigation. Considering the oral cavity which comprises a variety of different surfaces with a huge diversity of microorganisms, including more than 750 distinct taxa of bacteria, it is not surprising that one or more of these microbes would take part in the carcinogenesis of their habitat (26). Table 1 summarizes the infectious agents and related carcinogenic mechanisms in OSCC development.

The first species of bacteria that has been classified as a definitive cause of cancer in humans is Helicobacter pylori, which is associated with gastric adenocarcinoma (27). After this discovery many other possibilities were investigated. Gall bladder carcinoma was associated with Salmonella typhi, cervical carcinoma with Chlamydia trachomatis, lung cancer with Chlamydia pneumonia and intestinal cancer with Streptococcus bovis (28). No such direct link was established in OSCC. As mentioned before, the oral cavity is home to a rich microflora which changes composition and quantity from person to person and throughout the lifetime of an individual as a response to a variety of factors (26). In the studies with OSCC, it is essential to identify the organisms in the tumor specimens. Specific bacteria detected in the tumor specimen were Exiguobacterium oxidotolerans, Prevotella melaninogenica, Staphylococcus aureus and Veillonella paroula (29). In another study using saliva samples, out of 40 samples three bacteria were found to be elevated in OSCC, namely Capnocytophaga gingivalis, Prevotella meninogenica and Streptococcus mitis (30).

It has been suggested that specific oral bacteria play a part in carcinogenesis, either through induction of chronic inflammation or by interference, either directly or indirectly, with eukaryotic cell cycle and signaling pathways, or by metabolism of potentially carcinogenic substances like acetaldehyde causing mutagenesis (28). 
There are also a number of yeasts sharing the same environment with the bacteria. The most common yeast found in the human oral mucosa and generally regarded as commensals is a species of Candida (26). When host defense mechanisms are compromised or when changes occur in the local oral microenvironment Candida spp. act as 'opportunistic pathogens' leading to a wide range of oral mucosal infections (31). Besides being opportunistic, it has been shown that leukoplakia with candidal infection (formerly known as candidal leukoplakia) has a higher rate of malignant transformation than non-infected leukoplakia, and the estimated rate is up to $10 \%$ (32). Moreover, it has been observed that oral carriage of the most common type of candida, Candida Albicans, is higher in patients presenting with leukoplakia or OSCC than in patients without oral pathology (33). C. albicans may have a direct or indirect role in oral carcinogenesis. Candida might induce OSCC by directly producing carcinogenic compounds (e.g. nitrosamines) (26). The tubular hyphal structure of $C$. albicans is an important factor as it allows access of precursors from saliva and the release of nitrosamine product to keratinocytes, potentially initiating OSCC (34). In a recent study in a mouse model of oral carcinogenesis Dwivedi et al. (35), found that infection with C. albicans alone was not capable of inducing dysplasia or OSCC, but it was suggested that Candida creates an environment favorable to cell proliferation that may lead to clonal expansion of genetically altered cells. Alcohol consumption is a well-known risk factor in OSCC development. Although ethanol itself is not carcinogenic, its metabolites comprise highly toxic compounds such as acetaldehyde, hydoxyethyl radicals, ethoxy radicals, and hydroxyl radicals (31). The metabolism of alcohol starts in the oral cavity with the conversion of ethanol with enzymes catalyzed by alcohol dehydrogenase (ADH) from the epithelium and also from the oral microorganisms. Acetaldehyde in the mouth can also be derived from tobacco smoke, which contains a number of toxic aldehydes and other substances. Therefore tobacco and alcohol use has a synergistic effect on the risk of developing $\operatorname{OSCC}(5,26,31)$. From the molecular perspective, mucosal bacterial infections may influence carcinogenesis by inducing chronic inflammation in the adjacent connective tissue leading to upregulation of cytokines and growth factors. Similarly, C. albicans has been found to induce IL-8 secretion of endothelial cells by stimulating the cells to produce TNF-a $(31,36)$.The transcript factor NF-kB, a key coordinator of innate immunity and inflammation, is also an important tumor promoter $(14,15)$. Candidal infection may activate particular toll-like receptors (TLRs), which are known to be activated after tissue damage and microbial infection. They can also communicate with the tumor promoter NF-kB. NF-kB is involved in carcinogenesis, especially where cancer-related inflammation is evident. The association between $C$. albicans, TLR and NF-kB, and the production of cytokines and enzymes in the prostoglandin synthesis pathway, such as COX-2, is another potential mechanism that shows how C. albicans might influence the development of OSCC (31). Hooper et al. (26) suggested that 'Whether or not there is a causal relation between microbes and cancer, there is also a possibility that changes commensal microflora occur in conjunction with cancer development, which could have been used as a diagnostic indicator'. Meurman (37) proposed that it would be fascinating to control oral cancer by controlling oral microbes. The idea is truly fascinating and may not be as far-fetched as thought.

Apart from bacteria and yeasts there is also evidence that viruses take part in oral carcinogenesis. The role of the human papilloma viruses (HPV) and herpes simplex viruses (HSV) has been investigated in a number of studies $(38,39,40)$. More than 100 types of HPV are identified, but only 12 types of HPV isolated from the oral cavity were associated with 
malignant lesions, including HPV-2,-3,-6, -11,-13,-16,-18,-31,-33,-35,-52 and -57 (41). Studies indicated that HPV-16 and -18 were the most common types detected in individuals with OSCC (42). HPV-16 DNA, in particular, was detected predominantly in oropharyngeal SCCs located in the lingual and palatine tonsillar regions (39). Although the role of HPV in OSCC is smaller than in oropharyngeal cancers, it is important to distinguish HPV (+) OSCC since they are regarded as different entities $(43,44)$. HPV $(+)$ OSCC are clinically found at young ages and generally in subjects without tobacco or chronic alcohol consumption. The histologically well differentiated and faster growing cancers which respond to chemo-radiotherapy have a clinical outcome - in term of overall survival - better than HPV (-) OSCC patients (44).

Recent studies revealed a synergistic effect between alcohol and HPV, but surprisingly tobacco use did not affect their relation (45). The mechanism of oral carcinogenesis by HPV is related with the E6 and E7 genes. Its genome is made up of early genes (E) with a primary function of episomal replication and late genes (L), which encode viral capsid proteins (41). There are 7 early genes identified and two of these, E6 and E7, have the capacity to immortalize the keratinocytes through inactivation of tumor growth suppression genes p53 and Retinoblastoma $(\mathrm{Rb})$ respectively $(39,41)$. Generally, there is no clinic lesion or sign of inflammation in HPV (+) OSCC patients, but there is a relation proposed by Tezal et al. (40) that chronic inflammation in periodontal pockets may give an opportunity to initiate HPV infection and its persistency. In this study the base of tongue in squamous cell carcinoma patients were found to be $70 \%$ positive for HPV-16 and HPV $(+)$ tumors, and had significantly higher rates of alveolar bone loss, which is indicative of chronic periodontitis.

Infections in the oral cavity are likely to play a role in oral carcinogenesis. Since there are numerous factors that cannot yet be distinguished, further studies with larger sample sizes are warranted.

\begin{tabular}{lll}
\hline $\begin{array}{l}\text { Risk factor } \\
\text { Oral biofilm (Dental plaque) }\end{array}$ & $\begin{array}{l}\text { Potential carcinogenic mechanism } \\
\text { Induction of cellular proliferation, inhibition } \\
\text { of apoptosis, interference with cellular } \\
\text { signalling mechanisms } \\
\text { Mutagenic interaction with saliva } \\
\text { Microbial action on oncogenic inflammatory }\end{array}$ & $\begin{array}{l}\text { Reference } \\
\text { reactions and proto-oncogenes }\end{array}$ \\
& $\begin{array}{l}\text { Providing oppurtunity to initiate HPV } \\
\text { infection and serve resevoir for latent virus }\end{array}$ & 48 \\
& $\begin{array}{l}\text { Interference with cellular signalling } \\
\text { mechanism }\end{array}$ & 49 \\
Viridans streptococci & $\begin{array}{l}\text { Converting ethanol to acetaldehyde } \\
\text { Dysplastic changes in oral leukoplakia }\end{array}$ & 50 \\
Candida albicans & $\begin{array}{l}\text { Converting ethanol to acetaldehyde } \\
\text { Epithelial cell immortalization } \\
\text { Activation of proto-oncogenes inactivation } \\
\text { Human papilloma virus }\end{array}$ & 52 \\
Herpes simplex virus & 52 \\
\hline
\end{tabular}

Modified from ref 37.

Table 1. Infectious agents and attributed carcinogenic mechanisms in oral carcinogenesis 


\subsection{Non-Infectious chronic inflammation and OSCC}

Chronic inflammatory diseases such as ulcerative colitis, atrophic gastritis and Barret's esophagus (53) have been causally associated with cancer development. Within the oral cavity, the best example of chronic inflammation are periodontal disease (as mentioned before) and oral lichen planus (OLP), which is regarded as having a malignant potential in a wide range of $0-12,5 \%(48,53,54)$. OLP was proposed as a unique disease model for studying non-infectious chronic inflammation and its relation to cancer in a recent publication. In the tissue microenvironment of OLP it is expected to find cytokines/chemokines directly associated with oral carcinogenesis, and suggested that OLPrelated OSCC is very likely to develop from another pathway than non-OLP OSCC (53). Chronic traumas in the oral cavity were also associated with oral carcinogenesis in some recent studies and case reports $(55,56,57)$. Recently, we conducted a study on the etiological factors of tongue carcinoma. Patient and control groups each consisted of 30 male and 17 female subjects with mean ages 53,17 $( \pm 12,565)$ and 52,55 $( \pm 11,542)$ respectively. Smoking and alcohol abuse proportions were significantly higher in the patient group as expected ( $p=0.0001, p<0.0001$ respectively). Chronic traumas were observed in $44,7 \%$ of the patients and $17 \%$ of the control group $(p=0.004)$. On regression analysis chronic traumas, such as alcohol abuse or a family history of cancer and smoking $(p=0.0001)(58)$ appeared as significant etiologic factors.

We believe that field cancerization is evident in oral and orofarengeal mucosa (in the existence of epigenetic factors) with multiple steps of molecular changes starting from the first sign of dysplasia. In our opinion, the nuance is that, the site of chronic trauma reaches the point of cancer before any other competitive sites of oral mucosa. This finding might be supported by studies that associate inflammation with OSCC.

\section{Role of chemokines in cancer}

Chemokines are low molecular weight proteins (approximately $8-17 \mathrm{kDa}$ ) and were originally defined as potent attractants for leukocytes in all inflammatory settings - as well as being regarded as mediators of acute and chronic inflammation $(59,60)$. More than 45 non-allelic chemokine genes and more than 20 chemokine receptors, which interact combinatorial, have been identified in human genome (59). Chemokines are classified on the basis of the presence of variations on their cysteine group. The first group, the CC subfamily, is composed of 28 members, whereas the CXC subfamily comprises 17 members. The other two smaller subfamilies are the CX3C and XC families, and each is presented with one member. The CXC chemokines are further classified into ELR+ and ELR- subgroups based on presence or absence of their 'glu-leu-arg' motif. ELR+ CXC chemokines are angiogenic, whereas ELR- members (except CXCL12) function as angiostatic to inhibit the formation of blood vessels (60). These are shown in Table 2 with their subgroups, receptors and tumoral impacts.

Chemokines carry a great significance in many biological events, both in physiological such as embryogenesis, lymphoid organ development, in pathology as wound healing angiogenesis, Th1/Th2 development, leukocyte homeostasis and inflammatory diseases (25). Chemokines attract leukocytes to the site of inflammation. Chemokines affect both the pro- and anti-tumor effect in the tumor microenvironment by regulating immune cell infiltration (12). 


\begin{tabular}{|c|c|c|}
\hline Systematic name & Chemokine reseptor & $\mathrm{P} / \mathrm{M} / \mathrm{A}$ \\
\hline \multicolumn{3}{|l|}{$\begin{array}{l}\text { CXC chemokine } \\
\text { ELR+ chemokines }\end{array}$} \\
\hline CXCL1 & CXCR2>CXCR1 & $\mathrm{P}$ \\
\hline CXCL2 & CXCR2 & $\mathrm{P}$ \\
\hline CXCL3 & CXCR2 & $\mathrm{P}$ \\
\hline CXCL4 & Unknown & A \\
\hline CXCL5 & CXCR2 & $\mathrm{P}$ \\
\hline CXCL6 & CXCR1,CXCR2 & $\mathrm{P}$ \\
\hline CXCL7 & CXCR2 & $\mathrm{P}$ \\
\hline CXCL8 & CXCR1,CXCR2 & $\mathrm{P}$ \\
\hline \multicolumn{3}{|l|}{ ELR- chemokines } \\
\hline CXCL9 & CXCR3 & A \\
\hline CXCR10 & CXCR3 & A \\
\hline CXCR11 & CXCR3 & A \\
\hline CXCR12 & CXCR4,CXCR7 & $\mathrm{M}, \mathrm{P}$ \\
\hline CXCR13 & CXCR5 & \\
\hline CXCR14 & Unknown & $\mathrm{P}$ \\
\hline CXCR16 & CXCR6 & \\
\hline \multicolumn{3}{|l|}{ CC chemokine } \\
\hline CCL1 & CCR3 & $\mathrm{P}$ \\
\hline CCL2 & CCR2 & $\mathrm{P}$ \\
\hline CCL3 & $\mathrm{CCR} 1,5$ & $\mathrm{P}$ \\
\hline CCL3L1 & CCR1,5 & \\
\hline CCL4 & CCR5 & $\mathrm{P}$ \\
\hline CCL5 & CCR1,3,5 & $\mathrm{P}$ \\
\hline CCL6 & Unknown & \\
\hline CCL7 & CCR1,2,3 & $\mathrm{P}$ \\
\hline CCL8 & $\mathrm{CCR} 3,5$ & $\mathrm{P}$ \\
\hline CCL9/10 & CCR1 & \\
\hline CCL11 & CCR3 & $\mathrm{P}$ \\
\hline CCL12 & CCR3 & \\
\hline CCL13 & $\mathrm{CCR} 2,3$ & \\
\hline CCL14 & $\mathrm{CCR} 1,5$ & \\
\hline CCL15 & $\mathrm{CCR} 1,3$ & $\mathrm{P}$ \\
\hline CCL16 & CCR 1,2 & $\mathrm{P}$ \\
\hline CCL17 & CCR4 & \\
\hline CCL18 & Unknown & $\mathrm{P}$ \\
\hline CCL19 & CCR7 & $\mathrm{P}$ \\
\hline CCL20 & CCR6 & $\mathrm{P}$ \\
\hline CCL21 & CCR7 & P,lymph node metastasis \\
\hline CCL22 & CCR4 & \\
\hline CCL23 & CCR1 & $\mathrm{P} / \mathrm{M}$ \\
\hline CCL24 & CCR3 & \\
\hline CCL25 & CCR9 & \\
\hline CCL26 & CCR3 & \\
\hline CCL27 & CCR10 & \\
\hline CCL28 & CCR3,10 & \\
\hline \multicolumn{3}{|l|}{ C chemokine } \\
\hline XCL1 & XCL1 & \\
\hline \multicolumn{3}{|l|}{$C X_{3} C L 1$ chemokine } \\
\hline $\mathrm{CX}_{3} \mathrm{CL} 1$ & $\mathrm{CX}_{3} \mathrm{CL} 1$ & $\mathrm{P} / \mathrm{M}$ \\
\hline
\end{tabular}

P-tumor progression; M-metastasis; A-Angiostatic (Modified from ref 25)

Table 2. Chemokine superfamily and their receptors 
Leukocytes infiltrate the tumor in response to chemokines secreted by the tumor itself. This immune cell recruitment may promote anti-tumor activities such as elimination of tumor cells by macrophages and recruitment of innate and adaptive immune cells (25). As the tumor progresses, the attraction of immune cells by chemokines being secreted from the tumor tissue itself results in an accumulation of leukocytes in order to increase tumor growth and angiogenic mediators for tumor vasculature. Mostly, receptors of these particular chemokines are up-regulated in tumor cells which allow them to take advantage of the persistent chemokines in their microenvironment. Tumors act as immune cells which have the ability to secrete chemokines for progression. The best example is macrophages present in the tumor lesions which secrete chemokines involved in tumor cell proliferation and survival as well as angiogenesis and metastasis $(12,13)$. In studies based on solid tumors such as breast and prostate cancers, cancer cells were found to express higher levels of chemokine receptors CXCR4, CCR7, CCR9 and CCR10 (61, 62). This might explain the metastatic tropism of each type of cancer, depending on the receptor present on cancer cells and chemokines produced at the site of metastasis. The ligand of CXCR4, CXCL12, is best expressed in the lung, liver and lymph nodes, which are frequently involved in tumor metastasis. Moreover, CCL21, the ligand of CCR7, is produced by lymph nodes, and CCL27, the ligand of CCR10, is secreted by skin (63). The step of tumor progression includes growth of the primary tumor, angiogenesis and metastasis. The chemokines and their receptors described in these steps are as follows: CXCR4/CXCL12 is the most efficient chemokine/chemokine receptor pair in enhancing cell growth (60), CXCR2 ligands, CXCL1, CXCL2 and CXCL8 in promoting angiogenesis (64), CXCR4/CXCL12 (in bone metastasis), CCL19-CCL21/CCR7 (in lymph node metastasis) and CCL27/CCR10 (in skin metastasis) pairs in metastasis (63). Recently, chemokines and their receptors have been identified as molecular targets of cancer therapy. CXCR4 is the most targeted receptor in these studies since it was the first chemokine receptor found to be related with metastasis. CXCR4 antagonists significantly reduced the size of primary tumors in mouse models of melanoma, osteosarcoma, breast and prostate tumors (65). Another promising target is the angiogenic chemokine receptor, CXCR2, and antagonists for this receptor are under consideration for melanoma therapy. Some others, such as CCR5 antagonist, have been approved by the FDA for the treatment of HIV-infected patients. Clinical trials involving a CCR9 antagonist are also in progression for Crohn's disease (60).

\subsection{Chemokines and OSCC}

Ammar et al. (66) conducted one of the first studies in oral squamous cell carcinoma and chemokine expression and revealed the association of CXCR4 expression in primary site and lymph node metastasis, mode of invasion, tumor recurrence and prognosis of the patients. Parallel with this finding Ishikawa et al. (67) found a highly significant correlation $(p=0.0035)$ between CXCR4 expression and lymph node metastasis of OSCC. Another study on chemokine expression and OSCC was reported in 2004, investigating the role of tumorassociated macrophages in oral cavity and oropharyngeal squamous cell carcinoma. CCL2 was found to be up-regulated significantly in tumors compared with normal mucosa (68). Later on Ferreira et al. (69) reported the role of CCL2 in lymph node metastasis of OSCC. Lymph node metastasis was also associated with other chemokine expressions. For example, CCR7 was found to be significantly associated with five clinical factors, including lymph node metastasis. Other factors were large tumors, progressive stages, local recurrences and cancer death (70). 
The association of CCR7 expression and lymph node metastasis was confirmed by another study in 2009 that demonstrated CCL21 stimulation increased the ability of CCR7-positive cells, which in turn showed stronger adhesion to lymph nodes (71). Another axis related with lymph nodes was CCL3/CCR1. Silva et al. (72) reported that CCL3/CCR1 expression was significantly higher in OSCC patients than controls and they suggested that CCL3/CCR1 axis may have a role in the spread of tumoral cells to the lymph nodes.

CCL5/CCR5 axis is also studied in OSCC and found related with enhanced migration of oral cancer cells through the increase of matrix metalloproteinase (MMP)-9 production (73).

Beyond the expression profiles there is another important factor related with predisposition and progression of cancer. Single nucleotid polymorphisms (SNPs), in genes for susceptibility factors, may influence gene expression, protein function and disease predisposition in certain individuals (74). Recently, many studies revealed certain functional polymorphisms influencing expression of genes related with inflammation, and have been correlated with an increased risk for developing oral malignancies $(75,76,77)$. Vairaktaris et al. (74) studied polymorphisms of a group of interleukins and tumor necrosis factors $-\alpha$ and $-\beta 162$ OSCC patients. Among studied cytokines, IL-6 and TNF- $\alpha$ polymorphisms were found to be related with OSCC occurrence. Gupta et al. (78) confirmed the results of the previously mentioned study in tobacco-related OSCC in Asian Indians. They studied SNPs in TNF- $\alpha$ and TNF receptor genes and TNF- a -308 G/A was found related with susceptibility to OSCC. In a Southern Thailand study on polymorphism of proinflammatory cytokines genes, susceptibility to OSCC appeared to be influenced by variants in inflammatory and immunomodulatory genes (79). Another study, again from the Greek group, was published in 2009, showing that PAI-1, MMP-9, TIMP-2 and ACE polymorphisms, which effect their expression, contributed significantly in OSCC prediction (80). Currently there are not many studies on OSCC and polymorphism of chemokines. In one study for SDF-1 (CXCL12) and CCR5 polymorphisms in head-neck cancers, only SDF-1 genotypes among studied polymorphisms were found to be significantly different from the control group distribution and this was correlated with susceptibility of SCC of the head and neck - but salivary gland tumors were excluded (81). In the other study on CCR5 and its receptor CCL5 polymorphism conducted in Taiwan, 253 OSCC patients were enrolled and SNPs in CCL5-28 and -403 genes revealed increased risk for OSCC, whereas the combined effect of CLL5-28 CG and -403 TT genes were found to increase the risk of OSCC but reduce the clinicopathological development of OSCC patients (82).

There is also a recently published study about chemokine polymorphism and OSCC of our group from Istanbul University (83). We studied the CCL2/CCR2 axis since CCL2 has been identified as a major chemokine inducing the recruitment of macrophages in human tumors, including those of the bladder, cervix, ovary, lung and breast $(84,85,86,87,88)$. CCL2 expression was detected at the protein level in tumor cells, both in primary tumors and in the metastatic sites (89). Studies indicated that lower levels of CCL2 did form tumors but with substantial delay in onset and growth rate (90). It is shown that the polymorphism A2518G in the regulatory region of the CCL2 gene influences CCL2 expression in response to inflammatory stimuli (91). The level of expression may vary due to polymorphism in CCL2 and its receptor CCR2 (89). In Istanbul University we therefore studied CCL2 and its receptor CCR2 polymorphisms in OSCC, and to the best of our knowledge it was the first time in the literature. In this study, we hypothesized that genetic polymorphisms in 
chemokines and their receptors (CCL2 A-2518G and CCR2-V64I) are involved in leukocyte trafficking and may thus influence the risk of OSCC.

We found a statistically significant difference between the control and OSCC groups for CCL2 A2518G genotypes ( $p=0.012$ ). The frequencies of CCL2 2518 GG genotype and G allele in the OSCC group were higher than those of the control group $(p=0.043$ and $p=0.006$, respectively). Individuals carrying the $G$ allele (GG+AG genotypes) had a 1.89-fold increased risk for OSCC $\left(\mathrm{p}=0.011 ; \chi^{2}=6.45 ; \mathrm{OR}=1.89 ; 95 \% \mathrm{CI}=1.15-3.09\right)$.

The CCR2 V64I genotype frequencies for controls and cases were not significantly different $(p=0.08)$. CCR2 V64I wt/wt genotype frequency in the control group was higher than that of patient group $\left(\mathrm{p}=0.027 ; \chi^{2}=4.88\right)$ and individuals carrying the $64 \mathrm{I}$ allele and $\mathrm{wt} / 64 \mathrm{I}$ genotype had an increased risk for OSCC individuals ( $\mathrm{p}=0.027, \chi^{2}=4.88 ; \mathrm{p}=0.048 ; \chi^{2}=3.91$ respectively).

While CCL2 G allele, CCL2 GG genotype, CCR2 64I allele, gender, smoking and alcohol consumption were associated with OSCC in univariate analysis, only CCL2 G allele, CCR2 64I allele, gender and alcohol consumption were associated with this disease in multivariate logistic regression analysis.

Association of tumor progression and the possibility of CCL-2 A2518G and CCR2 V64I polymorphism playing a role in OSCC as a prognostic marker has been studied. No statistically significant differences were found between genotypes.

The genotype distributions of both CCL2 A-2518G and its receptors CCR2-V64I vary in many cancer studies $(92,93,94)$. Our findings indicated a relation between CCL2 A- 2518 GG genotype and $G$ allele and OSCC ( $p=0.043$ and $p=0.006$ respectively). It seems that individuals carrying the $G$ allele had increased risk for development of OSCC $(p=0.011)$. To our best knowledge, six papers have reported an association of CCL2 2518 A/G polymorphism with various cancer types including breast (93), bladder (95, 96), nasopharynx (94), endometrial (97) and non-small cell lung cancer (98). Among these studies CCL2 2518G GG genotype was found to be a risk factor in endometrial cancer (6.7fold increased risk) (97) and in bladder cancer (3-fold increased risk) (95). In a breast cancer study CCL2 2518 GG genotype and G allele frequency were also found to be significantly different ( $p=0.020$ and 0.026 respectively) in patients with metastatic tumors (93). These studies indicated that GG genotype and mutant $G$ allele stand on the tumor side as reported in our study. These results are also consistent with the report suggesting the association of $G$ allele with higher levels of CCL2 expression (89). However, in a nasopharynx cancer study (94), CCL2 2518G AA and AG genotypes, which were suggested to have an association with relatively lower expression of CCL2, were found to be more prone to distant metastasis than those with GG genotype. GG genotype and G allele were also found significantly decreased in non-small cell lung cancer (98) and bladder cancer (96) patients.

The CCR2 V64I wt/wt genotype frequency in the control group was higher than the patient group ( $\left.\mathrm{p}=0.027 ; \chi^{2}=4.88\right)$, and individuals carrying the $64 \mathrm{I}$ allele and $w \mathrm{t} / 64 \mathrm{I}$ genotype had increased risk to develop OSCC.

Although results presented in the current study have suggested that CCR2-V64I polymorphism leading to increased risk for OSCC is similar to bladder (95) and endometrial cancer (97) types in Turkish population, the other results related to hepatocellular carcinoma (99) and non-small cell lung cancers (98) remain controversial. 
These conflicting results may be explained in many different ways. First, as these studies were mostly conducted in different countries; ethnic differences may play a part. Several CCL2 A-2518G and CCR2-V64I polymorphism studies were conducted around the world, and the distribution of control group data in these studies reveals genetic variations in distinct geographic areas. These results strengthen the idea that ethnic variations affect gene polymorphisms. Secondly, all mentioned studies were unique in cancer types and none was repeated either in the same or different nation. Thirdly, the sample sizes in the studies are relatively small when compared with the number of patients in their own nation-including our study.

The current study is the first report showing the influences of CCL2 and its receptor CCR2 gene variants on OSCC. Our results suggest that the genetic variants in the CCL2 and CCR2 genes may be associated with susceptibility of OSCC in the Turkish population. We can speculate that CCL2 polymorphism might increase the biological activity of the CCR2 receptor and the development of OSCC risk within this group.

\section{Conclusion}

Inflammation is a recently defined contributor of oral carcinogenesis. In this multi-step process, inflammation might have a role in initiation as well as progression. Important components of this association are cytokines and chemokines produced by activated innate immune cells, which stimulate tumor growth and progression. Moreover, genetic susceptibility and gene/environment interactions are becoming more important in the attempt to eliminate the burden of cancer. The evidence found so far is sending out signals that OSCC may cease to exist in the future, and the referral will only be for a group of diseases that manifests symptoms of a similar sort. Further studies with larger sample groups in premalignant diseases of oral mucosa as well as OSCC are required to confirm these findings.

\section{Summary}

Oral cancer accounts more than $2 \%$ of all body cancers worldwide and more than $95 \%$ of them were found to be squamous cell carcinoma. Despite its relative rareness, high mortality rates (survival is not more than $50 \%$ in 5 years), which have not improved over the past 3 decades, have drawn the attention of the investigators. The well- known risk factors of oral squamous cell carcinoma (OSCC) like smoking, alcohol abuse and HPV infection, which are mainly based on life -style factors, seem inadequate to explain the increasing incidence especially among young population. In addition, genetic susceptibility may play an important role but the underlying mechanism of the disease still remains obscure.

Many theories about pathogenesis of the disease have been produced as a result of the clinical observations. One of the best known is about inflammation. Clinicians have experienced that tumor mass is almost always accompanied by an inflammatory zone and pathologists have always observed inflammatory cells in and around the tumors. This is not a new finding and in fact so old, which dates back to famous hypothesis by Virchow in 19th Century and even ancient back to Celsius in the year 50 BC. So what is new? The new issues are the molecular developments which elucidate many unanswered questions about cancer. The relation between inflammation and cancer was one of them. 
In clinical researches about the relationship between inflammation and cancer, oral squamous cell carcinoma has an important advantage which is being easily detected by naked eye. Our previous clinical studies about etiology of tongue squamous cell carcinomas revealed that chronic traumas and irritations which lead to chronic inflammation were associated with tongue SCC formation. This encouraged us to move another step into the molecular field to understand the mechanism.

It is suggested that the relationship between cancer and inflammation occurs through two pathways: an extrinsic pathway driven by inflammatory signals such as infections and an intrinsic pathway driven by genetic alterations that cause both inflammation and neoplasia. Main mediators at the intersection of these pathways include transcription factors and primary proinflammatory cytokines.

Chemokines are a family of cytokines which are important mediators of leukocyte trafficking. They involve in defense of microbial infection, angiogenesis and metastasis. Several important polymorphisms of chemokine and chemokine receptors which deregulate chemokine system have been found and it is suggested that they may interfere with inflammatory and other diseases.

This chapter will include a brief review of molecular mechanisms of inflammation that seem responsible for etiology, pathogenesis and prognosis of oral squamous cell carcinoma and the new findings of our study group on chemokine.

\section{References}

[1] Zini A, Czerninski R, Sgan-Cohen HD. Oral cancer over four decades: epidemiology, trends, histology, and survival by anatomic sites. J Oral Pathol Med 2010; 39: 299305.

[2] Parkin DM, Bray F, Ferlay J, Pisani P. Global cancer statistics, 2002. CA Cancer J Clin 2005; 55: 74-108.

[3] Warnakulasuriya S. Global epidemiology of oral and oropharyngeal cancer. Oral Oncol 2009; 45: 309-16.

[4] Warnakulasuriya S, Sutherland G, Scully C. Tobacco, oral cancer, and treatment of dependence. Oral Oncol 2005; 41: 244-60.

[5] Ogden GR and Wight AJ: Aetiology of oral cancer: Alcohol. BR J Oral Maxillofac Surg 1998; 36: 247-51.

[6] Syrjänen S. Human papillomavirus ( HPV ) in head neck cancer. J Clin Virol 2005; 32 (Suppl): 59-66.

[7] Llewellyn CD, Linklater K, Bell J, Johnson NW, Warnakulasuriya KAAS. Squamous cell carcinoma of the oral cavity in patients aged 45 years and under: a descriptive analysis of 116 cases diagnosed in the South East of England from 1990 to 1997. Oral Oncol 2003; 39: 106-14.

[8] Bleyer A. Cancer of the oral cavity and pharynx in young females: increasing incidence, role of human papilloma virus, and lack of survival improvement. Semin Oncol 2009; 36: 451-9.

[9] Bau DT, Tsai MH, Huang CY et al. Relationship between polymorphisms of nucleotide excision repair genes and oral cancer risk in Taiwan: evidence for modification of smoking habit. Chin J Physiol. 2007; 50: 294-300. 
[10] Hatagima A, Costa EC, Marques CF, Koifman RJ, Boffetta P, Koifman S. Glutathione Stransferase polymorphisms and oral cancer: a case-control study in Rio de Janeiro, Brazil. Oral Oncol 2008; 44: 200-7.

[11] Kietthubthew S, Sriplung H, Au WW, Ishida T. Polymorphism in DNA repair genes and oral squamous cell carcinoma in Thailand. Int J Hyg Environ Health 2006; 209: 21-9.

[12] Balkwill, F and Mantovani A. Inflammation and cancer: back to Virchow? Lancet 2001; 357: 539-45.

[13] Mantovani A, Allavena P, Sica A, Balkwill F. Cancer-related inflammation. Nature 2008; 24: 436-44.

[14] Aggarwal BB, Gehlot P. Inflammation and cancer: how friendly is the relationship for cancer patients? Current Opinion in Pharmacology 2009; 9: 351-69.

[15] Coussens LM, Werb Z. Inflammation and cancer. Nature 2002; 420:860-7.

[16] Brigati C, Noonan DM, Albini A, Benelli R. Tumors and inflammatory infiltrates: friends or foes? Clin Exp Metastasis 2002; 19: 247-58.

[17] Feiken E, Romer J, Eriksen J, Lund LR. Neutrophils express tumor necrosis factor-alpha during mouse skin wound healing. J Invest Dermatol 1995; 105: 120-3.

[18] Hubner G, et al. Differential regulation of pro-inflammatory cytokines during wound healing in normal and glucocorticoid-treated mice. Cytokine 1996; 8:548-56.

[19] Chedid M, Rubin JS, Csaky KG, Aaronson SA. Regulation of keratinocyte growth factor gene expression by interleukin 1. J Biol Chem 1994; 269:10753-7.

[20] Eming SA, Krieg T, Davidson JM. Inflammation in wound repair: Molecular and cellular mechanisms. J Oral Invest Dermatol 2007; 127: 514-25.

[21] Osusky R, Malik P, Ryan SJ. Retinal pigment epithelium cells promote the maturation of monocytes to macrophages in vitro. Ophthalmic Res 1997; 29: 31-6.

[22] Rossi D, Zlotnik A. The biology of chemokines and their receptors. Annu Rev Immunol 2000; 18: 217-42.

[23] Chensue SW, Ruth JH, Warmington K, Lincoln P, Kunkel SL. In vivo regulation of macrophage IL-12 production during type 1 and type 2 cytokine-mediated granuloma formation. J Immunol 1995; 155:3546-51.

[24] Romer J, et al. Impaired wound healing in mice with a disrupted plasminogen gene. Nature Med 1996; 2: 287-92.

[25] Raman D, Baugher PJ, Thu YM, Richmond A. Role of chemokines in tumor growth. Cancer Letters 2007; 256: 137-65.

[26] Hooper SJ, Wilson MJ, Crean SJ. Exploring the link between microorganisms and oral cancer: A systematic review of the literature. Head Neck 2009; 31: 1228-39.

[27] Correa P, Houghton J. Carcinogenesis of Helicobacter pylori. Gastroenterology 2007; 133: 659-72.

[28] Chocolatewala N, Chaturverdi P, Desale R. The role of bacteria in oral cancer. Indian Journal of Medical and Paediatric Oncology 2010; 31: 126-31.

[29] Hooper SJ, Crean SJ. Fardy MJ et al. A molecular analysis of the bacteria present within oral squamous cell carcinomas. J Med Microbiol 2007; 56: 1651-9.

[30] Mager DL, Haffajee AD, Devlin PM, Norris CM, Posner MR, Goodson JM. The salivary microbiota as a diagnostic indicator of oral cancer: A descriptive, non-randomized study of cancer-free and oral squamous cell carcinoma subjects. J Translational Med $2005 ; 3: 27$. 
[31] Bakri MM, Hussaini HM, Holmes AR, Cannon RD, Rich AM. Revisiting the association between candidal infection and carcinoma, particularly oral squamous cell carcinoma. J Oral Microbiol 2010; 2: 5780.

[32] Bartie KL, Williams DW, Wilson MJ, Potts AJ, Lewis MA. Differential invasion of Candida albicans isolates in an in vitro model of oral candidosis. Oral Microbiol Immunol 2004; 19: 293-6.

[33] McCullough M, Jaber M, Barret AW, Bain L, Speight PM, Porter SR. Oral yeast carriage correlates with presence of oral epithelial dysplasia. Oral Oncol 2002; 38: 391-3.

[34] Krogh P, Hald B, Holmstrup P. Possible mycological etiology of oral mucosal cancer: catalytic potential of infecting Candida albicans and other yeast in production of Nnitrosobenzyl-methylamine. Carcinogenesis 1987; 8: 1543-8.

[35] Dwivedi PP, Mallya S, Dongari-Bagtzoglou A. A novel immunocompetent murine model for Candida albicans-promoted oral epithelial dysplasia. Med Mycol 2009; 47: 157-67.

[36] Orozco AS, Zhou X, Filler SG. Mechanisms of the proinflammatory response of endothelial cells to Candida albicans infection. Infect Immun 2000; 68: 1134-41.

[37] Meuman JH. Infections and dietary risk factors of oral cancer. Oral Oncol 2010; 46: 4113.

[38] Shillitoe EJ. The role of viruses in squamous cell carcinoma of the oropharyngeal mucosa. Oral Oncol 2009; 45: 351-5.

[39] Gillison ML, D'Souza G, Westra W, Sugar E, Weihong Xiao, Begum S, Viscidi R. Distinct risk factor profiles for Human Papillomavirus type 16-positive and Human Papillomavirus type 16-negative head and neck cancers. J Natl Cancer Inst 2008; 100: 407-20.

[40] Tezal M, Nasca MS, Stoler DL, Melendy T, Hyland A, Smaldino PJ, Rigual NR, Loree TR. Chronic periodontitis-Human Papillomavirus synergy in base of tongue cancers. Arch Otolaryngol Head Neck Surg. 2009; 135: 391-6.

[41] Pinheiro RS, Franca TRT, Ferreira DC, Ribeiro CMB, Leao JC, Castro GF. Human Papillomavirus in the oral cavity of children. J Oral Pathol Med 2011; 40: 121-6.

[42] Miller CS, Johnstone B. Human Papillomavirus as a risk factor for oral squamous cell carcinoma: a meta-analysis, 1982-1997. Oral Surg Oral Med Oral Radiol Endod 2001; 91: 622-35.

[43] Machado J, Reis PP, Zhang T et al. Low prevalence of Human Papillomavirus in oral city carcinomas. Head Neck Oncol 2010; 2:6.

[44] Pannone G, Santoro A, Papagerakis A, Muzio LL, De Rosa G, Bufo P. The role of Human Papillomavirus in the pathogenesis of head and neck squamous cell carcinoma: an overview. Infectious Agents and Cancer 2011; 6:4.

[45] Smith EM, Ritchie JM, Summersgill KF, Hoffman HT, Wang DH, Haugen TH, Turek LP. Human Papillomavirus in oral exfoliated cells and risk of head and neck cancer. J Natl Cancer Inst 2004; 96: 449-55.

[46] Lax AJ, Thomas W. How bacteria could cause cancer: one step at a time. Trends Microbiol 2002; 10: 293-9.

[47] Bloching M, Reich W, Schubert J, Grummt T, Sandner A. The influence of oral hygiene on salivary quality in the Ames test, as a marker for genotoxic effects. Oral Oncol 2007; 43: 933-9. 
[48] Tezal M, Sullivan MA, Hyland A et al. Chronic periodontitis and the incidence of head and neck squamous cell carcinoma. Cancer Epidemiol Biomarkers Prev 2009; 18: 2406-12.

[49] Narikiyo M, Tanabe C, Yamada Y et al. Frequent and preferential infection of Treponema denticola, Streptococcus mitis, and streptococcus anginosus in esophageal cancers. Cancer Sci 2004; 95: 569-74.

[50] Homann N, Tillonen J, Meurman JH et al. Increased salivary acetaldehyde levels in heavy drinkers and smokers: a microbiological approach to oral cavity cancer. Carcinogenesis 2000; 21: 663-8.

[51] Nieminen MT, Uittamo J, Salaspuro M, Rautemaa R. Acetaldehyde production from ethanol and glucose by non-Candida albicans yeasts in vitro. Oral Oncol 2009; 45: e245-8.

[52] Park NH, Li SL, Xie JF, Cherrick HM. In vitro and animal studies of the role of viruses in oral carcinogenesis. Eur J Cancer B Oral Oncol 1992; 28B: 145-52.

[53] Liu Y, Messadi DV, Wu H, Hu S. Oral lichen planus is a unique disease model for studying chronic inflammation and oral cancer. Medical Hypotheses 2010; 75: 492-4.

[54] Gandolfo S, Richiardi L, Carrozo M et al. Oral Oncol 2004; 40: 77-83.

[55] Piemonte ED, Lazos JP, Brunotto M. Relationship between chronic trauma of the oral mucosa, oral potentially malignant disorders and oral cancer. J Oral Pathol Med 2010; 39:513-7.

[56] Compilato D, Cirillo N, Termine N et al. Long-standing oral ulcers: proposal for a new 'S-C-D classification system' J Oral Pathol Med 2009; 38: 241-53.

[57] Gallego L, Junquera L, Llorente S. Oral carcinoma associated with implant-supported overdenture trauma: a case report. Dental Traumatol 2009; 25: e3-e4.

[58] Bektaş-Kayhan K, Ünür M, Hafiz G, Karadeniz A, Altun M, Meral R. Carsinoma of the tongue: A case-control study on etiologic factors and dental trauma. Oral Oncol 2007; (supp 2):154-155.

[59] Rollins BJ. Inflammatory chemokines in cancer growth and progression. Eur J Cancer 2006; 42: 760-7.

[60] Lazennec G, Richmond A. Chemokines and chemokine reseptors: new insights into cancer-related inflammation Trends Mol Med 2010; 16: 133-44.

[61] Ali S, Lazennec G. Chemokines: novel targets for breast cancer metastasis. Cancer Metastasis Rev 2007; 26: 401-20.

[62] Vindrieux D, Escobar P, Lazennec G. Emerging roles of chemokines in prostate cancer. Endocr Relat Cancer 2009; 16: 663-73.

[63] Ben-Baruch A. Organ selectivity in metastasis: regulation by chemokines and their receptors. Clin Exp Metastasis 2008; 25: 345-56.

[64] Mehrad B, Keane MP, Strieter RM. Chemokines as mediators of angiogenesis. Thromb Haemost 2007; 97: 755-62.

[65] Allavena P, Germano G, Marchesi F, Mantovani A. Chemokines in cancer related inflammation. Exp Cell Res 2011; 317: 664-73.

[66] Ammar A, Uchida D, Begum NM et al. The clinicopathological significance of the expression of CXCR4 protein in oral squamous cell carcinoma. Int J Oncol 2004; 25: 65-71. 
[67] Ishikawa T, Nakashiro K, Hara S et al. H.CXCR4 expression is associated with lymphnode metastasis of oral squamous cell carcinoma. Int J Oncol 2006; 28: 61-6.

[68] Marcus B, Arenberg D, Lee J et al. Prognostic factors in oral cavity and oropharyngeal squamous cell carcinoma. Cancer 2004; 12: 2779-87.

[69] Ferreira FO, Ribeiro FL, Batista AC, Leles CR, de Cássia Gonçalves Alencar R, Silva TA. Association of CCL2 with lymph node metastasis and macrophage infiltration in oral cavity and lip squamous cell carcinoma. Tumour Biol 2008; 29: 114-21.

[70] Tsuzuki H, Takahashi N, Kojima A, Narita N, Sunaga H, Takabayashi T, Fujieda S. Oral and oropharyngeal squamous cell carcinomas expressing CCR7 have poor prognoses. Auris Nasus Larynx 2006; 33: 37-42.

[71] Shang ZJ, Liu K, Shao Z. Expression of chemokine receptor CCR7 is associated with cervical lymph node metastasis of oral squamous cell carcinoma. Oral Oncol. 2009; 45: 480-5.

[72] Chuang JY, Yang WH, Chen HT et al. CCL5/CCR5 axis promotes the motility of human oral cancer cells. J Cell Physiol 2009; 220: 418-26.

[73] Silva TA, Ribeiro FLL, Oliveira-Neto $\mathrm{HH}$ et al. Dual role of CCL3/CCR1 in oral squamous cell carcinoma: Implications in tumor metastasis and local host defense. Oncol Rep 2007; 18: 1107-13.

[74] Vairaktaris E, Yapijakis C, Serefoglou Z et al. Gene expression polymorphisms of interleukins- 1 beta, $-4,-6,-8,-10$, and tumor necrosis factors-alpha, -beta: regression analysis of their effect upon oral squamous cell carcinoma. J Cancer Res Clin Oncol 2008; 134: 821-32.

[75] Tsai MH, Chen WC, Tsai CH, Hang LW, Tsai FJ. Interleukin-4 gene, but not the interleukin-1 beta gene polymorphism, is associated with oral cancer. J Clin Lab Anal 2005; 19: 93-8.

[76] Wong YK, Chang KW, Cheng CY, Liu CJ. Association of CTLA-4 gene polymorphism with oral squamous cell carcinoma. J Oral Pathol Med 2006; 35: 51-4.

[77] Vairaktaris E, Yiannopoulos A, Vylliotis A et al. Strong association of interleukin-6 -174 $\mathrm{G}>\mathrm{C}$ promoter polymorphism with increased risk of oral cancer. J Biol Markers 2006; 21: 246-50.

[78] Gupta R, Sharma SC, Das SN. Association of TNF-a and TNFR1 promoters and 3' UTR region of TNFR2 gene polymorphisms with genetic susceptibility to tobaccorelated oral carcinoma in Asian Indians. Oral Oncol 2008; 44: 455-63.

[79] Kietthubthew S, Wickliffe J, Sriplung H, Ishida T, Chonmaitree T, Au WW. Association of polymorphisms in proinflammatory cytokine genes with the development of oral cancer in Southern Thailand. Int J Hyg Environ Health 2010; 213: 146-52.

[80] Vairaktaris E, Serefoglou Z, Avgoustidis D et al. Gene polymorphisms related to angiogenesis, inflammation and thrombosis that influence risk for oral cancer. Oral Oncol 2009; 45: 247-53.

[81] Khademi B, Razmkhah M, Efrani N, Gharagozloo M, Ghaderi A. SDF-1 and CCR5 genes polymorphism in patients with head and neck cancer. Pathol Oncol Res 2008; 14: $45-50$.

[82] Weng CJ, Chien MH, Kin CW et al. Effect of CC chemokine ligand 5 and CC chemokine receptor 5 genes polymorphisms on the risk and clinicopathological development of oral cancer. Oral Oncol 2010; 46: 767-72. 
[83] Bektas-Kayhan K, Unur M, Boy-Metin Z, Cakmakoglu B. MCP-1 and CCR2 gene variants in oral squamous cell Oral Diseases (2011) doi:10.1111/j.16010825.2011.01843.x

[84] Amann B, Perabo FG, Wirger A, Hugenschmidt H, Schultze- Seemann W. Urinary levels of monocyte chemoattractant protein-1 correlate with tumour stage and grade in patients with bladder cancer. Br J Urol 1998; 82: 118- 21.

[85] Riethdorf L, Riethdorf S, Gutzlaff K, Prall F, Loning T. Differential expression of the monocyte chemoattractant protein-1 gene in human papillomavirus-16-infected squamous intraepithelial lesions and squamous cell carcinomas of the cervix uteri. Am J Pathol 1996; 149: 1469-76.

[86] Negus RP, Stamp GW, Relf MG et al. The detection and localization of monocyte chemoattractant protein-1 (MCP-1) in human ovarian cancer. J Clin Invest 1995; 95: 2391- 6 .

[87] Arenberg DA, Keane MP, DiGiovine B et al. Macrophage infiltration in human nonsmall-cell lung cancer: the role of CC chemokines. Cancer Immunol Immunother 2000; 49: 63- 70 .

[88] Ueno T, Toi M, Saji H et al. Significance of macrophage chemoattractant protein-1 in macrophage recruitment, angiogenesis, and survival in human breast cancer. Clin Cancer Res 2000; 6: 3282- 9 .

[89] Soria G and Ben-Baruch A. The inflammatory chemokins CCL2 and CCL5 in breast cancer. Cancer Letters 2008; 267: 271-85.

[90] Conti I, Rollins BJ. CCL2 (monocyte chemoattractant protein-1) and cancer. Semin Cancer Biol 2004; 14: 149-54.

[91] Rovin BH, Lu L, Saxena R. A novel polymorphism in the $M C P-1$ gene regulatory region that influences MCP-1 expression. Biochem Biophys Res Commun 1999; 259: 344- 8.

[92] Yeh CB, Tsai HT, Chen YC et al. Genetic polymorphism of CCR2-64I increased the susceptibility of hepatocellular carcinoma. J Surg Oncol 2010; 102: 264-70.

[93] Ghilardi G, Biondi ML, Torre A, Battaglioli L, Scorza R. Breast cancer progression and host polymorphism in the chemokine system: Role of macrophage chemoattractant protein-1 (MCP-1) -2518 G allele. Clin Chem 2005; 51: 452-5.

[94] Tse K, Tsang N, Chen K et al. MCP-1 promoter polymorphism at -2518 is associated with metastasis of nasopharyngeal carcinoma after treatment. Clin Cancer Res 2007; 13: 6320-6.

[95] Narter KF, Agachan B, Sozen S, Cincin ZB, Isbir T. CCR2-64I is a risk factor for development of bladder cancer. Genet Mol Res 2010; 9: 685-92.

[96] Vázquez-Lavista LG, Lima G, Gabilondo F and Llorente L Genetic association of monocyte chemoattractant protein 1 (MCP-1)-2518 polymorphism in Mexican patients with transitional cell carcinoma of the bladder. Urology 2009; 74: 414-8.

[97] Attar R, Agachan B, Kuran SB et al. Association of CCL2 and CCR2 gene variants with endometrial cancer in Turkish women. In Vivo 2010; 24: 243-8.

[98] Yang L, Shi GL, Song CX, XU SF. Relationship between genetic polymorphism of MCP1 and non-small-cell lung cancer in Han nationality of North China. Genetics and Molecular Res 2010; 9: 765-71.

[99] Nahon P, Sutton A, Rufat P et al. Chemokine system polymorphism, survival and hepatocellular carcinoma occurrence in patients with hepatitis $C$ virus-related cirrhosis. World J Gastroenterol 2008; 14: 713-9. 


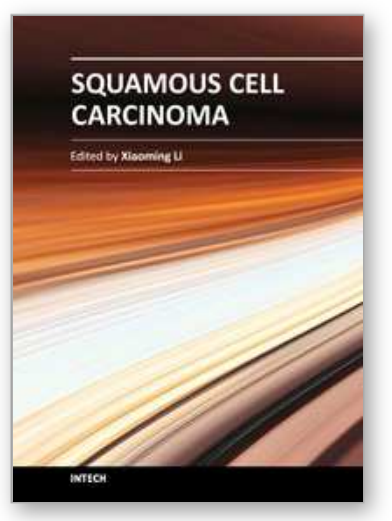

\author{
Squamous Cell Carcinoma
}

Edited by Prof. Xiaoming Li

ISBN 978-953-51-0024-9

Hard cover, 302 pages

Publisher InTech

Published online 03, February, 2012

Published in print edition February, 2012

This book points to some new areas for investigation on squamous cell carcinoma (SCC). Firstly, the features and management of some specific SCC is discussed to give the readers the general principles in dealing with these uncommon and sophisticated conditions. Some new concepts in adjuvant therapy including neoadjuvant therapy and gold nanoparticle-based photo dynamic therapy are introduced. Secondly, a detailed discussion of molecular aspects of tumor invasion and progression in SCC is provided with the emphasis on the roles of some important factors. The role of tumor microenvironment in head and neck SCC is specifically discussed. Thirdly, the roles of cancer stem cells (CSC) in cancer therapy of SCC are described. Molecular mechanisms involving therapeutic resistance and new therapeutic strategies targeting CSC are discussed in detail. Finally, other aspects concerning SCC are included, which involve the assessment, genetic manipulation and its possible clinical implications for the treatment of SCC.

\title{
How to reference
}

In order to correctly reference this scholarly work, feel free to copy and paste the following:

Kıvanç Bektaş-Kayhan (2012). Role of Inflammation in Oral Squamous Cell Carcinoma, Squamous Cell Carcinoma, Prof. Xiaoming Li (Ed.), ISBN: 978-953-51-0024-9, InTech, Available from:

http://www.intechopen.com/books/squamous-cell-carcinoma/role-of-inflammation-in-oral-squamous-cellcarcinoma

\section{INTECH}

open science | open minds

\section{InTech Europe}

University Campus STeP Ri

Slavka Krautzeka 83/A

51000 Rijeka, Croatia

Phone: +385 (51) 770447

Fax: +385 (51) 686166

www.intechopen.com

\section{InTech China}

Unit 405, Office Block, Hotel Equatorial Shanghai

No.65, Yan An Road (West), Shanghai, 200040, China

中国上海市延安西路65号上海国际贵都大饭店办公楼 405 单元

Phone: +86-21-62489820

Fax: $+86-21-62489821$ 
(C) 2012 The Author(s). Licensee IntechOpen. This is an open access article distributed under the terms of the Creative Commons Attribution 3.0 License, which permits unrestricted use, distribution, and reproduction in any medium, provided the original work is properly cited. 